Arq. Bras. Med. Vet. Zootec., v.67, n.1, p.315-318, 2015

\title{
Comunicação
}

[Communication]

\section{Capim-piatã adubado com fontes de fósforo de diferente solubilidade em água}

[Piata palisadegrass fertilized with different sources of phosphorus for solubility in water]

C.F.D. Duarte ${ }^{1}$, L.M. Paiva ${ }^{2}$, H.J. Fernandes ${ }^{2}$, D.L. Prochera ${ }^{1}$, L.H. Cassaro ${ }^{1}$, M.F. Breure ${ }^{1}$, L.S. Flores ${ }^{1}$, R.L. Fernandes ${ }^{1}$, E.R.C. Souza ${ }^{1}$, A.C. Fleitas ${ }^{1}$, K.R.S. Falcão ${ }^{1}$

${ }^{1}$ Alunos de graduação - Universidade Estadual de Mato Grosso do Sul - UEMS - Aquidauana, MS

${ }^{2}$ Universidade Estadual de Mato Grosso do Sul - UEMS - Aquidauana, MS

No Brasil, onde a produção pecuária baseia-se principalmente na alimentação em pasto, a baixa fertilidade do solo e o manejo incorreto das pastagens são as principais causas da degradação e diminuição da produtividade do setor. Consequências disso são a redução da massa forrageira e do valor nutritivo da pastagem.

Rezende et al. (2011) demonstraram que o fósforo foi o nutriente mais limitante à produção de forragem, comprometendo o crescimento das plantas e o desenvolvimento radicular. Na região do Cerrado brasileiro, o fósforo foi um dos nutrientes mais importantes para o estabelecimento, recuperação e renovação de pastagens (Freire et al., 2000). Nesse bioma, dentre as sérias limitações à produção agropecuária, sobressaem-se a acidez e baixos teores de nutrientes do solo, com destaque para o fósforo.

A produção animal sustentável tem sido o foco de pesquisas em todo o mundo. Nesse sentido, destacam-se os estudos com adubação fosfatada de fontes de diferentes solubilidades em água, minimizando a frequência de adubações, reduzindo as chances de degradação e demanda pela abertura de novas áreas para produção, bem como a perda desse elemento por percolação no solo.

Objetivou-se com este trabalho avaliar o desenvolvimento do capim-piatã adubado com fontes de fósforo de diferentes solubilidades em água.

A fase do trabalho descrita foi desenvolvida no período de fevereiro a agosto de 2012, em oito hectares da Fazenda da UEMS, Unidade Universitária de Aquidauana, localizada no município de Aquidauana, Mato Grosso do Sul, latitude $20^{\circ} 28^{\prime} \mathrm{S}$; longitude $55^{\circ} 48^{\prime} \mathrm{W}$ e altitude de 149 metros. O clima da região, segundo a classificação de Köppen, é Tropical Úmido (AW), dividido em duas estações, a chuvosa (outubro a março) e a seca (abril a setembro). Os dados climáticos do período experimental foram obtidos pela Agraer (2012), na Tabela 1.

Realizou-se amostragem e análise do solo da área experimental, cujos resultados estão apresentados na Tabela 2.

Tabela 1. Dados climáticos (temperatura, umidade e pluviosidade) observados durante o período experimental

\begin{tabular}{llllll}
\hline & Março & Abril & Maio & Junho & Média \\
\hline $\mathrm{T}^{\circ}$ Máx. & 33,8 & 34,5 & 33,3 & 34,4 & 34 \\
$\mathrm{~T}^{\circ}$ Mín. & 20,4 & 16,1 & 11,0 & 10,9 & 14,6 \\
Umid. (\%) & 45,0 & 31,0 & 28,0 & 25,0 & 32,25 \\
Chuva (mm) & 260,8 & 56,2 & 4,6 & 8,2 & 82,45 \\
\hline
\end{tabular}

Fonte: Agraer (2012).

Recebido em 12 de março de 2014

Aceito em 3 de outubro de 2014

E-mail: camilafernandesd@hotmail.com 
Tabela 2. Análise química do solo

\begin{tabular}{|c|c|c|c|c|c|c|c|c|c|c|c|c|c|}
\hline p & & $\mathrm{P}$ & MO & K & $\mathrm{Ca}$ & $\mathrm{Mg}$ & $\mathrm{Ca}+\mathrm{Mg}$ & $\mathrm{Al}$ & $\mathrm{H}$ & $\mathrm{Al}+\mathrm{H}$ & $S$ & $\mathrm{~T}$ & $\mathrm{~V}$ \\
\hline $\mathrm{CaCl}_{2}$ & Água & $\mathrm{Mg} / \mathrm{dm}^{3}$ & $\mathrm{~g} / \mathrm{dm}^{3}$ & \multicolumn{10}{|c|}{$\mathrm{Cmol} / \mathrm{dm}^{3}$} \\
\hline 5,11 & 5,74 & 43,75 & 18,05 & 0,78 & 2,15 & 0,90 & 3,05 & 0,00 & 3,17 & 3,17 & 3,83 & 7,00 & 54,71 \\
\hline
\end{tabular}

Não houve necessidade de correção da acidez do solo. O preparo do solo foi feito através de duas gradagens leves, para limpar a área, romper os blocos de terra e permitir a substituição da forrageira já implantada pelo capim-piatã.

A área total foi subdividida em 16 piquetes de 0,5 ha cada, distribuídos em quatro blocos. Os tratamentos avaliados foram: controle (sem aplicação de adubação fosfatada); fonte lenta (Fosfato Natural Reativo - FNR); fonte prontamente disponível (Superfosfato Simples SS); e fonte mista de fósforo (FH Pastagem ${ }^{\circledR}$ produto comercial da Fertilizantes Heringer).

Os tratamentos foram distribuídos a lanço, nas seguintes quantidades: $\mathrm{SS}=150 \mathrm{~kg} \mathrm{ha}^{-1}(27 \%$ de $\left.\mathrm{P}_{2} \mathrm{O}_{5}\right) ; \mathrm{FNR}=103,5 \mathrm{~kg} \mathrm{ha}^{-1}\left(23,5 \%\right.$ de $\left.\mathrm{P}_{2} \mathrm{O}_{5}\right) ; \mathrm{FH}$ $=97 \mathrm{~kg} \mathrm{ha}^{-1}\left(16,5 \%\right.$ de $\mathrm{P}_{2} \mathrm{O}_{5}$ solúvel em água e $21,3 \%$ de $\mathrm{P}_{2} \mathrm{O}_{5}$ solúvel em ácido cítrico). O capim-piatã (B. brizantha $\mathrm{cv}$. BRS-Piatã) foi semeado três dias depois, na quantidade de $10 \mathrm{~kg}$ de sementes $\mathrm{ha}^{-1}$. Práticas de cultivo, como limpeza manual de invasoras, foram realizadas quando necessário.

Após 90 dias da semeadura, foram marcados com fios coloridos e identificados com varas de bambu dez perfilhos por piquete, para medição semanal das características estruturais e determinação das seguintes características nas plantas: Taxa de aparecimento foliar (TApF); Filocrono (Filo); Taxa de alongamento foliar (TAlF); Duração de vida das folhas (DVF); Taxa de senescência de lâminas foliares (TSeF); Taxa de alongamento do colmo (TAlC); Número de folhas vivas por perfilho (NFV). Considerou-se folha viva aquela com mais de $50 \%$ de seu limbo verde, sem sinais de senescência.

Para determinação da relação parte aérea:raiz (PA:R), foram coletadas amostras totais das plantas em quatro pontos distintos em cada piquete. As amostras foram coletadas com canos de PVC de diâmetro de $15 \mathrm{~cm}$, considerando a planta toda - parte aérea e raiz, até a profundidade de $10 \mathrm{~cm}$.

As amostras foram lavadas, separadas em parte aérea, raiz e material morto, acondicionadas individualmente, devidamente identificadas, em sacos de papel previamente pesados, e encaminhadas à estufa de ventilação forçada com temperatura de $60^{\circ} \mathrm{C}$, para pré-secagem. Após 72 horas, o material foi retirado, pesado para determinação de Amostra Seca ao Ar (ASA), moído em moinho de facas, em peneira de $2 \mathrm{~mm}$ e, nessas amostras, determinada a Matéria Seca (MS). Com base nesses dados, posteriormente foram realizados os cálculos da PA:R das amostras.

Todas as características determinadas foram comparadas segundo um modelo em blocos casualizados e as médias, comparadas com o tratamento controle pelo teste de Dunnett e, entre $\mathrm{si}$, pelo teste $\mathrm{t}$ de student. $\mathrm{O}$ nível de significância de $5 \%$ foi adotado em todas as análises.

Não se observou diferença significativa $(\mathrm{P}>0,05)$ em nenhuma das características avaliadas (Tab. 3).

Tabela 3. Características morfogênicas, estruturais e relação parte aérea:raiz (PA:R) do capim-piatã em resposta a fontes de fósforo com diferente solubilidade em água

\begin{tabular}{|c|c|c|c|c|c|}
\hline \multirow{3}{*}{ Característica } & \multicolumn{4}{|c|}{ Tratamentos } & \multirow{3}{*}{$\begin{array}{l}\text { C.V. } \\
(\%)\end{array}$} \\
\hline & \multirow{2}{*}{ Controle } & \multicolumn{3}{|c|}{ Fontes de Fósforo } & \\
\hline & & $\mathrm{FH}$ & FNR & SS & \\
\hline TAlF $\left(\mathrm{cm} \mathrm{dia}^{-1}\right)$ & 2,24 & 2,83 & 2,33 & 2,50 & 23,8 \\
\hline TAlC $\left(\mathrm{cm} \mathrm{dia}^{-1}\right)$ & 0,405 & 0,480 & 0,323 & 0,400 & 38,4 \\
\hline DVF (dias) & 100 & 114 & 105 & 109 & 6,47 \\
\hline NFV (número de folhas vivas perfilho-1 ${ }^{-1}$ & 5,39 & 5,94 & 5,76 & 5,88 & 6,65 \\
\hline PA:R & 0,942 & 0,947 & 0,949 & 0,945 & 0,88 \\
\hline
\end{tabular}


Sbrissia et al. (2001) observaram que as características morfogênicas e estruturais são reguladas por fatores ambientais e influenciadas pelas características do pasto e do próprio perfilho. A interação entre esses determina o ritmo morfogênico das plantas (Sbrissia et al., 2003).

Infere-se que as condições climáticas interferiram e restringiram o desenvolvimento do pasto aqui avaliado. Essa cultivar necessita de uma temperatura média ideal para crescimento em torno de $35^{\circ} \mathrm{C}$ e uma precipitação média acima de $100 \mathrm{~mm} / \mathrm{mês}$ (Almeida et al., 2009). Com base nesses parâmetros, apesar de a temperatura estar próxima à ideal, a precipitação pluviométrica no período experimental não foi suficiente para permitir um desenvolvimento adequado das gramíneas (Tab. 1).

Duarte (2012) considerou a deficiência hídrica a mais prejudicial ao desenvolvimento das plantas. Esse autor destacou que a diminuição na disponibilidade hídrica prejudicou diversos processos, sendo a divisão e a expansão celular os primeiros a serem afetados. Assim, a deficiência hídrica observada no período experimental retardou o crescimento das folhas e caules, afetando a taxa de crescimento das gramíneas tropicais como um todo.

Dos Santos et al. (2002) correlacionaram essa deficiência hídrica e o menor desenvolvimento vegetal com uma baixa assimilação de nutrientes pelas plantas, em função da baixa atividade fotossintética. Esse baixo requerimento de fósforo pelas plantas no período avaliado pode ter mascarado as diferenças de disponibilidade desse elemento no solo entre os diversos tratamentos.

Outro aspecto a ser destacado refere-se ao efeito do nível de fertilidade do solo da área experimental sobre os resultados. Como pode ser observado na Tab. 2, os níveis de nutrientes encontrados no solo da área experimental não demandaram grande aporte nutricional. Nesse contexto, a não observância de diferença entre os tratamentos, nesse primeiro ano de avaliação, pode ser justificada pela excelente fertilidade do solo da área.

Sousa et al. (2004) observaram que uma menor relação parte aérea:raiz tem sido apontada como mecanismo importante para proporcionar uma maior eficiência de absorção de $\mathrm{P}$ pelas plantas, dada a baixa mobilidade desse nutriente no solo. Os altos valores de relação PA:R aqui observados, inclusive no tratamento controle (Tab. 3), indicam uma alta disponibilidade de $\mathrm{P}$ no solo da área experimental, quando comparada à demanda desse nutriente pelas plantas. A Tab. 2 também evidencia níveis elevados de $\mathrm{P}$ no solo da área.

As plantas forrageiras possuem um elevado requerimento inicial de fósforo. Como a solubilização do fosfato natural dá-se ao longo de vários anos, essas fontes de $\mathrm{P}$ de baixa solubilidade não podem fornecer esse aporte inicial requerido pelas plantas (Souza e Lobato, 2004). Os autores ainda consideram pertinente a estratégia de se aplicar no plantio o fosfato natural conjuntamente com uma fonte solúvel de fósforo

Por fim, Maciel et al. (2007) observaram que, somente no segundo ano de experimento, diferentes fontes de fósforo e sua interação com diferentes tipos de solo influenciaram significativamente a produção de Brachiaria brizantha.

Conclui-se então que, em solo de boa qualidade nutricional para as plantas e em condições de baixa disponibilidade hídrica, a adubação fosfatada com fontes de diferentes solubilidades em água não interferiu no desenvolvimento do capim-piatã no primeiro ano após implantação. É importante, no entanto, que se avaliem essas respostas em um período mais abrangente de tempo, para se observarem os efeitos das fontes menos solúveis aqui avaliadas no médio e longo prazo.

Palavras-chave: Brachiaria brizantha cv. BRSPiatã, caracterização morfogênica, fertilizantes fosfatados 


\begin{abstract}
The development of piatã grass fertilized with phosphorus sources with different solubilities in water was evaluated. The experiment was developed in the unit of Aquidauana of UEMS, MS, from February to August, 2012. Four treatments were evaluated: control (without phosphorus fertilization), slow solubility, fast solubility (readily available), and mixed solubility sources of phosphorus (FH Pasture®). It was adopted a randomized blocks design with four blocks and four replicates in a total of 16 pastures (0.5 ha each one). Measurements were performed weekly to evaluate structural characteristics and morphogenic variables of the plants. Data were submitted to a variance analysis according to the model. When necessary, the means of treatments with different phosphorus fertilizer sources were compared with the control using the Dunnett test and with other treatments by using student's t test. The significance level of $5 \%$ was adopted in all analysis. No significant effect was observed $(P<0.05)$ in the evaluated traits in the first year of the experiment.
\end{abstract}

Keywords: Brachiaria brizantha BRS-Piata, characterization morphogenic, phosphate fertilizers

\section{REFERÊNCIAS}

AGÊNCIA DE DESENVOLVIMENTO AGRÁRIO E EXTENSÃO RURAL. Boletins Meteorológicos. 2012. Disponível em: $<\mathrm{http}: / / \mathrm{www}$.agraer.ms.gov.br/cemtec/index.php ?inside $=1 \&$ tp $=3 \&$ show $=2524>$ Acessado em: 10 Nov 2012.

ALMEIDA, R.G. de; COSTA, J.A.A.; KICHEL, A.N. et al. Taxas e Métodos de Semeadura para Brachiaria brizantha cv. BRS Piatã em Safrinha. Campo Grande: Embrapa Gado de Corte, 2009. 12p. (Embrapa Gado de Corte. Comunicado Técnico, 113).

DUARTE, A.L.M. Efeito da água sobre o crescimento e o valor nutritivo das plantas forrageiras. Pesquisa \& Tecnologia, v.9, p.1-6, 2012.

FREIRE, F.M.; FONSECA, D.M.; CANTARUT-TI, R.B. Manejo da fertilidade do solo em pastagens. Informe Agropec., v.26, p.4453, 2005.

MACIEL, G.A.; COSTA, S.E.G.V.A; FURTINI NETO, A.E. et al. Efeitos de diferentes fontes de fósforo na Brachiaria brizantha cv. Marandu cultivada em dois tipos de solos. Cienc. Anim. Bras., v.8, p.227-233, 2007.

REZENDE, A.V.; LIMA, J.F.; RABELO, C.H.S. et al. Características morfofisiológicas da Brachiaria brizantha $\mathrm{cv}$. Marandu em resposta à adubação fosfatada. Rev. Agrarian, v.4, p.335343, 2011.
SANTOS, H.Q.; FONSECA, D.M.; CANTARUTTI, R.B. et al. Níveis críticos de fósforo no solo e na planta para gramíneas forrageiras tropicais, em diferentes idades. Rev. Bras. Cienc. Solo, v.26, p.173-182, 2002.

SBRISSIA, A.F.; DA SILVA, S.; CARVALHO, C.A.B. et al. Tiller size/population density compensation in Coastcross grazed swards. Sci. Agríc., v.58, p.655-665, 2001.

SBRISSIA, A.F; SILVA, S. MATTHEW, C. et al. Tiller size/density compensation in grazed Tifton 85 bermudagrass swards. Pesquisa Agropecuária Brasileira, v.38, p.1459-1468, 2003.

SOUSA, D.M.G.; MARTHA-JUNIOR, G.B.; VILELA, L. Manejo da Adubação fosfatada em Pastagens. In: PEDREIRA, C.G.S.; MOURA, J.C.; FARIA, V.P. Fertilidade do Solo para Pastagens Produtivas. Anais do Simpósio sobre Manejo de Pastagem: Piracicaba, 2004. p.101138.

SOUZA, M.G.; LOBATO, E. Adubação fosfatada em solos da região de cerrado. In: ANAIS DO SIMPÓSIO SOBRE FÓSFORO NA AGRICULTURA BRASILEIRA. Piracicaba: ANDA, 2004. 76p. 